\title{
Gender Identity and Sex Role of Patients Operated on for Bladder Exstrophy-Epispadias
}

\section{Taskinen, Seppo}

2016-08

Taskinen , S , Suominen , J S \& Mattila , A K 2016 , ' Gender Identity and Sex Role of Patients Operated on for Bladder Exstrophy-Epispadias ', Journal of Urology, vol. 196 , no. 2 , pp. 531-535 . https://doi.org/10.1016/j.juro.2016.02.2961

http://hdl.handle.net/10138/224091

https://doi.org/10.1016/j.juro.2016.02.2961

publishedVersion

Downloaded from Helda, University of Helsinki institutional repository.

This is an electronic reprint of the original article.

This reprint may differ from the original in pagination and typographic detail.

Please cite the original version. 


\title{
Gender Identity and Sex Role of Patients Operated on for Bladder Exstrophy-Epispadias
}

\author{
Seppo Taskinen,* Janne S. Suominen and Aino K. Mattila \\ From the Department of Pediatric Surgery, Children's Hospital, Helsinki University Hospital and University of Helsinki, \\ Helsinki and Department of Adult Psychiatry, Tampere University Hospital, Tampere (AKM), Finland
}

Purpose: We evaluated whether genital deformity has an impact on gender identity and sex role in patients operated on for bladder exstrophy-epispadias complex.

Materials and Methods: A total of 62 adolescents and adults operated on for bladder exstrophy-epispadias complex were mailed questionnaires evaluating gender identity (Gender Identity/Gender Dysphoria Questionnaire for Adolescents and Adults) and sex role (Bem Sex Role Inventory). Of the patients 33 responded and the results were compared with 99 gender matched controls.

Results: On the gender identity questionnaire female patients had median scores similar to those of their gender matched controls (4.93 vs $4.89, \mathrm{p}=0.412)$ but in males the score was lower compared to controls ( 4.87 vs $4.96, p=0.023)$, indicating somewhat more conflicted gender identity. However, no patient had gender dysphoria. Female sex role index was higher in female patients vs controls (5.9 vs $5.3, \mathrm{p}=0.003$ ) but was comparable between male patients and controls (5.2 vs $5.0, \mathrm{p}=0.459)$. Masculine sex role indices were comparable between female patients and controls as well as between male patients and controls. Of 32 patients 17 were considered to have androgynous sex role, as were 24 of 97 controls $(p=0.004)$. The exact diagnosis (bladder exstrophy or epispadias) or dissatisfaction with appearance of the genitals had no impact on gender identity or on sex role indices.

Conclusions: Male patients had lower gender identity scores compared to controls and female sex role was enhanced among female patients. Androgynous sex role was more common in patients vs controls. Gender dysphoria was not noted in any patient.

Key Words: bladder exstrophy, disorders of sex development, epispadias, gender identity

SURGERY of the external genitalia in children suffering from genital malformations has been a subject of debate in the last few decades. One argument against surgery has been that it is impossible to predict in early childhood how patient gender identity is going to evolve naturally. Development of gender identity has been associated with multiple factors such as genes, hormonal environment, differentiation of the brain, the gonads, fertility, internal genital organs, external genital appearance and social surroundings. ${ }^{1,2}$ Usually all of these factors are considered when treating patients with disorders of sex development. Previously

\section{Abbreviations and Acronyms \\ $\mathrm{BE}=$ bladder exstrophy \\ $\mathrm{BEEC}=$ bladder exstrophy- epispadias complex \\ $\mathrm{BSRI}=$ Bem Sex Role Inventory \\ DSD $=$ disorders of sex \\ development \\ $F=$ femininity \\ GIDYQ-AA = Gender Identity/ \\ Gender Dysphoria Questionnaire \\ for Adolescents and Adults \\ $\mathrm{M}=$ masculinity \\ VAS $=$ visual analogue scale}

Accepted for publication February 24, 2016 No direct or indirect commercial incentive associated with publishing this article.

The corresponding author certifies that, when applicable, a statement(s) has been included in the manuscript documenting institutional review board, ethics committee or ethical review board study approval; principles of Helsinki Declaration were followed in lieu of formal ethics committee approval; institutional animal care and use committee approval; all human subjects provided written informed consent with guarantees of confidentiality; IRB approved protocol number: animal approved project number

Study received hospital ethical committee approval. Permission for recruiting volunteer student sample was granted by University of Tampere Medical School Planning Group of Undergraduate Medical Education.

* Correspondence: Children's Hospital, University of Helsinki, Stenbäckinkatu 11, 00290 Helsinki, Finland (telephone: 358-50-4272542; FAX: 358-9-47175314; e-mail: seppo.taskinen@ hus.fi, seppo.taskinen@gmail.com).

See Editorial on page 305. 
gender assignment to females in $\mathrm{XY}$ males was practiced to some extent even in patients with severe structural anomalies not considered to be disorders of sex development., ${ }^{3,4}$ However, such an approach has mostly been abandoned due to poor results. ${ }^{1,4-6}$

Although it seems that there is no need for gender reassignment in patients with pure structural anomalies and gender identity may be influenced by many individual and social factors, the issue of whether abnormal genitalia and multiple surgeries have an impact on individual gender identity or sex role has not been properly investigated. We speculate that patients with bladder exstrophy or epispadias are an appropriate group in which to evaluate this problem as there is no known hormonal background behind those malformations, and all males and many females undergo extensive reconstructive genital surgery. In addition, despite multiple surgeries, patients are often dissatisfied with the external genitalia. ${ }^{7}$ We evaluated whether severe genital abnormality, multiple surgeries and unsatisfactory appearance of the genitalia influence gender identity and sex role by examining adults operated on for bladder exstrophy-epispadias complex in childhood.

\section{PATIENTS AND METHODS}

The operative database of the Children's Hospital, University of Helsinki was retrospectively reviewed for patients operated on for BE or epispadias between 1956 and 1992. A total of 67 patients were identified. Four patients had died and a mailing address was not found for 1 patient. Questionnaires were mailed up to 3 times to the remaining 62 patients. The hospital ethical committee approved the study.

A total of 33 patients $(53 \%)$ responded to the questionnaire. Of the patients 22 were male (13 with exstrophy and 9 with epispadias) and 11 were female ( 6 with exstrophy and 5 with epispadias). All 46XY individuals were raised as males. Baseline data (diagnosis, age, gender, performed operations) on patients were collected from the hospital records. Characteristics of participants and nonparticipants were comparable in terms of gender, diagnosis (epispadias, BE), age, number of anesthesias and kidney function in childhood. Median number of general anesthesias was 15 (range 4 to 30 ) in the 26 patients in whom exact numbers were available.

The control group was composed of a cohort of 257 medical students who filled out gender identity and sex role questionnaires voluntarily in seminars in 3 different years. Permission for recruiting the volunteer student sample was given by the Planning Group of Undergraduate Medical Education at the University of Tampere Medical School. Each patient had 3 gender matched controls whose ages were as close to the patient age as possible. Median ages of 22 male patients and 66 male controls were 26.5 (range 15 to 52 ) and 25 years (23 to 47 ), respectively $(\mathrm{p}=0.765)$. Median ages of 11 female patients and 33 female controls were 27 (range 19 to 45 ) and 27 years ( 23 to 40$)$, respectively $(\mathrm{p}=0.764$.)

Gender identity was measured with the Finnish version of the 27-item GIDYQ-AA, which is designed to assess the level of gender dysphoria and how well the respondents identify with their assigned gender. ${ }^{8,9}$ The adult versions for females and males were used in this study. The English version of the GIDYQ-AA questionnaire is validated for transgender/transsexual patients but the Finnish version has been used in patients with disorders of sex development. ${ }^{10}$ The GIDYQ-AA was chosen because we were unaware of any other gender identity/dysphoria questionnaire existing in Finnish. Statements on the GIDYQ-AA are rated on a 5-point Likert scale ranging from 1 (always) to 5 (never). Three items are reverse coded and the item concerning dreams can be left blank. GIDYQ-AA is formed by dividing the composite score of the scale by the number of responses and theoretically ranges from 1 to 5 . Lower scores indicate more problems with gender identity and scores below 3 indicate gender identity disorder..$^{8,9}$

Sex role orientation was assessed using the Finnish 30 item version of the Bem Sex Role Inventory. ${ }^{11-13}$ This tool consists of 2 gender role subscales, BSRI M (10 items) and BSRI F (10 items), plus 10 neutral filler items that were not used in this study. The items on BSRI M describe culturally desirable male traits, ie assertiveness, leadership ability, dominance, strong personality, forcefulness, aggressiveness, willingness to take a stand, independence, defense of own beliefs and willingness to take risks. The items on BSRI F describe culturally desirable female traits, ie understanding, sympathy, eagerness to soothe hurt feelings, sensitivity to needs of others, compassion, love of children, affection, gentleness, warmth and tenderness. Statements are rated on a 7-point Likert scale ranging from 1 (never or almost never) to 7 (always or almost always).

BSRI $\mathrm{M}$ and BSRI $\mathrm{F}$ indices were formed by summing up the items on the respective scales and then dividing the composite scores by 10 . Higher indices indicated a stronger trait. If the indices on the masculinity and femininity scales were above the median value in the same sex patients and controls, the person was described as having androgynous traits. ${ }^{14}$ One male patient with epispadias and 2 male controls did not fill out the BSRI questionnaire.

Some additional data concerning gender identity and satisfaction with the appearance of the genitalia were elicited as follows. Patients indicated on a VAS how strongly they perceived themselves as male or female (from 0, indicating totally male, to 100 , indicating totally female). Satisfaction with the appearance of the genitalia was gauged by the question, "Are you satisfied with the appearance of your external genitalia?" The response options were 1 , fully satisfied; 2 , fairly satisfied; 3 , somewhat satisfied; 4, fairly dissatisfied, and 5, totally dissatisfied. Patients were considered satisfied if they selected the option of fully, fairly or somewhat satisfied.

Results of the BSRI and GIDYQ-AA questionnaires are expressed as median (IQR). Mann-Whitney U test was 
Table 1. Comparison of cases and controls by GIDYQ-AA, and sexual identity of individuals evaluated by VAS

\begin{tabular}{|c|c|c|c|}
\hline & No. & $\begin{array}{l}\text { Median GIDYQ-AA } \\
\text { Index (IOR) }\end{array}$ & $\begin{array}{l}\text { Median VAS } \\
\text { (IOR) }\end{array}$ \\
\hline \multicolumn{4}{|c|}{ Female } \\
\hline Medical students & 33 & $4.89(4.77-4.96)^{*}$ & \\
\hline $\begin{array}{l}\text { Cases: } \\
\text { BEEC }\end{array}$ & 11 & $4.93(4.82-5.00)^{*}$ & $100(91-100)$ \\
\hline Epispadias & 5 & $4.96(4.68-5.00)$ & \\
\hline Exstrophy & 6 & $4.93(4.85-5.00)$ & \\
\hline Satisfactory genitals & 7 & $5.00(4.88-5.00)$ & \\
\hline Poor genitals & 2 & $4.87(4.82-4.93)$ & \\
\hline \multicolumn{4}{|c|}{ Male } \\
\hline Medical students & 64 & $4.96(4.89-5.00) \dagger$ & \\
\hline $\begin{array}{l}\text { Cases: } \\
\text { BEEC }\end{array}$ & 22 & $4.87(4.70-5.00) \dagger$ & $(0-6)$ \\
\hline Epispadias & 9 & $4.83(4.70-5.00)$ & \\
\hline Exstrophy & 13 & $4.89(4.83-4.98)$ & \\
\hline Satisfactory genitals & 13 & $4.89(4.79-4.97)$ & \\
\hline Poor genitals & 8 & $4.85(4.69-5.00)$ & \\
\hline
\end{tabular}

GIDYQ-AA questionnaire was different for females and males.

${ }^{*} p=0.412$.

$\dagger p=0.023$.

used to compare continuous variables, and Fisher exact test was used to compare categorical variables using StatView ${ }^{\circledR}$ 5.0.1. A p value of less than 0.05 was considered significant.

\section{RESULTS}

All males experienced themselves as more male than female, and all except 1 female felt more female than male based on the VAS (table 1). According to the GIDYQ-AA questionnaire, no patient had gender dysphoria (GIDYQ-AA index less than 3.00), and the female patient with $\mathrm{BE}$ who experienced herself more as male on the VAS had a GIDYQ-AA index of 4.82 , indicating no gender identity problems. The gender identity of female patients was similar to that of female controls (4.93 vs $4.89, \mathrm{p}=0.412$ ) but in males the index was lower (4.87 vs $4.96, \mathrm{p}=0.023$, table 1). The exact diagnosis (BE or epispadias) or dissatisfaction with the appearance of the genitals (10 patients) or sexual activity (15 males and 9 females) was not significantly associated with gender identity in either patient group.

The female sex role index was higher in female compared to male patients or female controls (5.9 vs 5.2 and $5.3, \mathrm{p}<0.001$ and $\mathrm{p}=0.003$, respectively) but comparable between male patients and controls (5.2 vs $5.0, \mathrm{p}=0.459$, table 2 ). Masculine sex role indices, in turn, were higher in male vs female patients (5.2 vs $4.9, \mathrm{p}=0.036$ ) but comparable between female patients and controls, as well as between male patients and controls (4.9 vs 4.6 and 5.2 vs 5.0, $\mathrm{p}=0.531$ and $\mathrm{p}=0.469$, respectively, table 2 ). Exact diagnosis (BE or epispadias) or dissatisfaction with genitals did not have a significant impact on either feminine or masculine BSRI indices in either patient group. An androgynous sex role was more common among patients than controls (17 of 32 patients and 24 of 97 controls, $\mathrm{p}=0.004)$.

\section{DISCUSSION}

In the present study gender identity and sex roles were evaluated in adolescent and adult patients operated on for BE or epispadias. Although these patients are not classified as having DSD, they have faced multiple genital surgeries similar to patients with DSD. Despite treatment, a third of the patients were dissatisfied with the external genitalia.

All male patients perceived themselves as more male than female, and all female patients except 1 felt themselves more female than male but no patient had gender dysphoria according to the GIDYQ-AA questionnaire. The GIDYQ-AA index was lower among male patients (4.87) vs controls (4.96), although in male patients the index was still approximately the

Table 2. Comparison of cases and controls by BSRI

\begin{tabular}{|c|c|c|c|c|c|}
\hline & No. & Median BSRI F Index (IQR) & $p$ Value & Median BSRI M Index (IQR) & $\mathrm{p}$ Value \\
\hline Medical students & 33 & $5.3(4.8-5.8)$ & $<0.003$ & $4.6(4.5-5.0)$ & 0.531 \\
\hline Epispadias & 5 & $5.9(5.8-6.2)$ & & $4.9(3.9-5.5)$ & \\
\hline Exstrophy & 6 & $5.9(5.7-6.5)$ & & $5.0(4.6-5.2)$ & \\
\hline Satisfactory genitals & 7 & $5.9(5.7-6.4)$ & & $4.9(4.2-5.2)$ & \\
\hline \multicolumn{6}{|c|}{ Male } \\
\hline $\begin{array}{l}\text { Medical students } \\
\text { Cases: }\end{array}$ & 64 & $5.0(4.5-5.5)$ & $<0.001$ & $5.0(4.6-5.4)$ & 0.469 \\
\hline BEEC & 22 & $5.2(4.6-5.8)$ & & $5.2(4.6-5.5)$ & \\
\hline Epispadias & 9 & $5.2(4.8-5.3)$ & & $5.1(4.7-5.3)$ & \\
\hline Exstrophy & 13 & $5.6(3.9-5.8)$ & & $5.3(4.5-5.7)$ & \\
\hline
\end{tabular}


same as it was in heterosexual males (4.85) in a previous study by Deogracias et al, in which patients with gender identity disorder scored a notably lower index on average (2.56). ${ }^{8}$ Whether such a difference (4.87 vs 4.96) is of clinical importance remains unknown. On the other hand, in female patients the feminine gender role was enhanced when compared to female controls. In addition, approximately half of the patients scored above the median on the femininity and masculinity scales of the BSRI, indicating an androgynous sex role. This stance may not be pathological as it has even been suggested that androgyny may be associated with better mental health, ${ }^{15}$ and an androgynous sex role also was found in roughly a fourth of our controls. ${ }^{16}$

In the past occasional gender reassignment has been done from male to female in genetically male individuals who have had very severe genital malformations. Followup of these patients has revealed that many of them live as males further in life. ${ }^{4,5} \mathrm{In}$ patients with BEEC gender reassignment from male to female has apparently been rare. However, also in these conditions the abnormality of the external genitalia is severe. For example male newborns with supposed aphallia are occasionally referred to our tertiary hospital, although the condition turns out to be epispadias.

In a study of genetically male patients with cloacal exstrophy raised as either males or females all had male typical behavior. ${ }^{5}$ We are not aware of earlier series of patients with BEEC evaluating gender identity and sex role. However, there are some studies analyzing the sexual functioning and psychological well-being of these patients, with variable results. ${ }^{17-25}$ Our group has previously analyzed these factors in our patients, with encouraging results. ${ }^{26,27}$

Our study has limitations. The anatomy of the external genitalia was variable at diagnosis among our patients, and we were unable to evaluate this factor in detail due to the retrospective nature of our study. Also the quality and number of operations were variable and difficult to evaluate. The participation rate of 53\% may have skewed the results, and the low number of females makes it difficult to draw conclusions concerning women. The GIDYQ-AA questionnaire has not been validated in patients with DSD, although we have used it previously in patients with DSD. ${ }^{10}$ In addition, we could not evaluate the effect of patient rearing in our analysis, and we cannot be sure whether our results can be applied to other cultures. However, our patient material is unselected and nationally representative since almost all patients in our country have been treated at our hospital. The control group comprising medical students was not ideal, but they were approximately the same age as the patients and the GIDYQ-AA index was close to the values of heterosexual university students in another study. ${ }^{8}$

\section{CONCLUSIONS}

Male patients with BEEC had slightly lower gender identity scores compared to controls, and the female sex role was enhanced among women with BEEC. However, gender dysphoria was not noted among the patients. Multiple operations and occasionally poor results with the genitalia were not associated with gender identity. This study supports the modern concept that genital anatomy itself has a limited role in gender identity and sex role. ${ }^{1,2,4}$ Accordingly other factors such as chromosomes, gonads, hormones and possible fertility should be major determinants of gender assignment in patients with severe genital malformations. All of these aspects should be discussed with the families and, when possible, the patients when making treatment plans.

\section{REFERENCES}

1. Mouriquand PD: Possible determinants of sexual identity: how to make the least bad choice in children with ambiguous genitalia. BJU Int, suppl., 2004; 93: 1.

2. Saraswat A, Weinand M and Safer JD: Evidence supporting the biologic nature of gender identity. Endocr Pract 2015; 21: 199.

3. Diamond DA, Burns JP, Huang $L$ et al: Gender assignment for newborns with 46XY cloacal exstrophy: a 6-year followup survey of pediatric urologists. J Urol, suppl., 2011; 186: 1642.

4. Meyer-Bahlburg HF: Gender identity outcome in female-raised $46, X Y$ persons with penile agenesis, cloacal exstrophy of the bladder, or penile ablation. Arch Sex Behav 2005; 34: 423.
5. Reiner WG and Gearhart JP: Discordant sexual identity in some genetic males with cloacal exstrophy assigned to female sex at birth. $\mathrm{N}$ Engl J Med 2004; 350: 333.

6. Reilly JM and Woodhouse CR: Small penis and the male sexual role. J Urol 1989; 142: 569

7. Gargollo PC and Borer JG: Contemporary outcomes in bladder exstrophy. Curr Opin Urol 2007; 17: 272.

8. Deogracias JJ, Johnson LL, Meyer-Bahlburg HF et al: The gender identity/gender dysphoria questionnaire for adolescents and adults. J Sex Res 2007; 44: 370.
9. Singh D, Deogracias JJ, Johnson LL et al: The gender identity/gender dysphoria questionnaire for adolescents and adults: further validity evidence. J Sex Res 2010; 47: 49.

10. Mattila AK, Fagerholm R, Santtila P et al: Gender identity and gender role orientation in female assigned patients with disorders of sex development. J Urol 2012; 188: 1930.

11. Bem SL: The measurement of psychological androgyny. J Consult Clin Psychol 1974; 42: 155.

12. Choi N, Fuqua DR and Newman JL: Exploratory and confirmatory studies of the structure of the Bem sex role inventory short form with two divergent samples. Educ Psychol Meas 2009; 69: 696 . 
13. Colley A, Mulhern G, Maltby $\mathrm{J}$ et al: The short form BSRI: instrumentality, expressiveness and gender associations among a United Kingdom sample. Pers Individ Dif 2009; 46: 384.

14. Bem SL: Gender schema theory: a cognitive account of sex typing. Psychol Rev 1981; 88: 354.

15. Lefkowitz ES and Zeldow PB: Masculinity and femininity predict optimal mental health: a belated test of the androgyny hypothesis. J Pers Assess 2006; 87: 95.

16. Rammsayer TH and Troche SJ: Sexual dimorphism in second-to-fourth digit ratio and its relation to gender-role orientation in males and females. Pers Individ Dif 2007; 42: 911.

17. Diseth TH, Bjordal R, Schultz A et al: Somatic function, mental health and psychosocial functioning in 22 adolescents with bladder exstrophy and epispadias. J Urol 1998; 159: 1684.

18. Ebert A, Scheuering S, Schott $G$ et al: Psychosocial and psychosexual development in childhood and adolescence within the exstrophyepispadias complex. J Urol 2005; 174: 1094.

19. Lee C, Reutter HM, Grässer MF et al: Genderassociated differences in the psychosocial and developmental outcome in patients affected with the bladder exstrophy-epispadias complex. BJU Int 2006; 97: 349.

20. Pennison MC, Mednick L, Rosoklija I et al: Health related quality of life in patients with bladder exstrophy: a call for targeted interventions. J Urol, suppl., 2014; 191: 1553.

21. Schaeffer AJ, Yenokyan G, Alcorn K et al: Health related quality of life in adolescents with bladder exstrophy-epispadias as measured by the Child Health Questionnaire-Child Form 87. J Urol 2012; 188: 1924.

22. Deans R, Liao LM, Wood D et al: Sexual function and health-related quality of life in women with classic bladder exstrophy. BJU Int 2015; 115: 633
23. Wilson CJ, Pistrang N, Woodhouse CR et al: The psychosocial impact of bladder exstrophy in adolescence. J Adolesc Health 2007; 41: 504.

24. Reiner WG and Gearhart JP: Anxiety disorders in children with epispadias-exstrophy. Urology 2006; 68: 172.

25. Reiner WG, Gearhart JP and Kropp B: Suicide and suicidal ideation in classic exstrophy. J Urol, suppl., 2008; 180: 1661.

26. Taskinen S, Suominen JS and Mattila AK Health-related quality of life and mental health in adolescents and adults operated for bladder exstrophy and epispadias. Urology 2015; 85: 1515.

27. Suominen JS, Santtila P and Taskinen S: Sexual function in patients operated on for bladder exstrophy and epispadias. J Urol 2015; 194: 195 